\title{
A study on sedimentation characteristic according to concentration change of top soil lost by flood
}

\author{
유실토양의 농도변화에 따른 침강특성에 대한 연구 \\ Young-Bong Jeon · Seon-Hong Kang* \\ 전영봉 · 강선홍* \\ Department of Environmental Engineering, Kwangwoon University \\ 광운대학교 환경공학과
}

\begin{abstract}
Sediment basin that is typical facility installed for development business to prevent soil erosion has low removal efficiency and therefore, it causes complaints from the residents and has a bad effect on ecosystem.

Thus there is a limit to control soil erosion using the existing design methods of sediment basin, so the purposes of this study is providing suitable design factors for sediment basin with regarding soil characteristic of development areas and analysing sedimentation characteristic by inflow concentration changes.

The results, for analyzing the sedimentation characteristic by soil concentrations within approximately 2,000 20,000 mg/L of initial SS concentration, indicated similar sedimentation trends for same soil in the supernatant regardless of initial concentrations. However, for different soil characteristic (percent finer), there are different results in sedimentation rate and concentrations of the supernatant.

Thus it is recommended that sediment basin to prevent soil erosion during construction should be designed based on retention time derived from soil sedimentation experiments regardless of inlet concentration. In addition, installing the soil erosion prevention facility at the back to satisfy effluent water quality should be considered to minimize soil erosion effectively.
\end{abstract}

Key words : Sediment basin, settling pond, soil erosion, initial SS concentration

주제어 : 침사지, 침전지, 토양유실, 초기 SS 농도

\section{1. 서 론}

공사시 발생하는 비점오염원 중에서는 부유물 질의 비중이 매우 높으며 부유물질의 대부분은 토 양으로 이루어져 있다.

이러한 토양의 유실은 토양과 우수가 존재하면 일어나며 유실된 토양은 하천이나 호수에서 유입 되어 부유물과 침전물을 만드는 것이 자연적인 현 상으로서, 국토의 개발행위로 인하여 토양유실이

- Received 22 September 2014, revised 08 October 2014, accepted 10 October 2014.

${ }^{*}$ Corresponding author: Tel : 82-2-940-5075 Fax : 82-2-911-2033 E-mail : seonhong@kw.ac.kr
더욱 증대되고 있다.

현재 토양유실을 방지하기 위하여 설치되는 대 표적 저감시설인 침사지 설계는 유입농도를 토사 유출 원단위로 산정하고 제거효율과 체류시간은 토양의 입경 분포를 분석하여 제거 가능한 입경을 선정 후 입경이 차지하는 비율로 저감효율을 산정 하는 방식을 채택하고 있다.

National disaster management institute (2008)는 효율적인 설계포착 입경을 $0.2 \mathrm{~mm}$ 로 채택하고 침강속도 $21 \mathrm{~m} / \mathrm{sec}$, 저류시간 1 시간 으로 설계한 침사지를 설치할 때 제거효율이 약 
40\%미만으로 나타나 2006년 국토해양부 토사 유출 저감목표 $80 \%$ 에 훨씬 미달하므로 추가적 인 토양유실 저감시설의 설치가 필요하다고 주 장하였다. Huh, Tae-Jung(2011)은 도로 및 자 연형 하천조성 공사시에 입경 분포 분석을 통해 설치된 침사지의 제거효율이 $18 \sim 28 \%$ 로 매우 낮아 인근 주민들의 민원 발생하여 추가시설을 설치하였다고 하였다.

이에 Kang, Chang-Hwan(2013)은 토사유 실을 억제하기 위해서는 소규모 환경영향평가 및 환경영향평가 단계에서 현황조사시 표토의 질, 논의 담수상태, 경사도, 경사장, 토지이용 현황, 토성, 용적밀도 등의 조사와 아울러, 저감 방안 수립에 필요한 토양의 침강실험이 반드시 필요하다고 제안하였다.

또한 개발사업 공사시 효율적인 표토유실 방 지를 위해서는 지구내 토양의 침강실험결과와 함께 체류시간을 고려한 저류지 설계가 이루어 져야 하고, 공사장 외부 유출 농도기준은 수용하 천의 홍수시 부유물질 현황 농도 내지 외국과 같 이 $50 \mathrm{mg} / \mathrm{L}$ 로 규제하여야 한다고 제안하였다.

따라서 본 연구에서는 개발지역의 토양 특성 을 반영하고 유입수 농도변화에 따른 침강특성 을 분석하여 적정한 침사지 설계인자를 도출하 고자 하였다.

\section{2. 연구내용 및 방법}

\section{1 연구대상지역 선정}

연구대상지는 대규모 토공사가 이루어져 토 사유실이 발생할 것으로 예상되는 진천신척 산 업단지 조성지역과 인천구월 주택단지 조성지역 을 선정하였다.

연구대상지중 진천신척 지역은 공사시 토사 유출로 주변 민원이 발생하였으며, 인천구월지 역은 해안지역의 점토로 이루어진 농경지역을 주택단지로 건설함에 따라 표토의 교란이 많이 일어나고 미세입경의 표토유실이 급격히 진행될 것으로 예상되어 선정하였다.

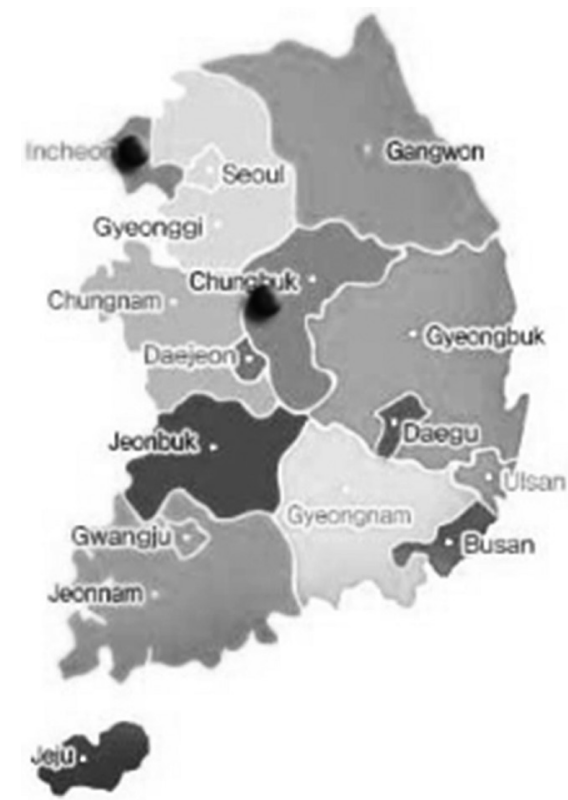

Fig. 2.1. Study area.

\section{2 침강실험}

공사중인 진천신척지역과 인천구월지역에서 원지반토와 절토지역의 시료를 채취하여 토양시 료로 실험에 이용하였다. 본 연구에서는 실험지 표를 $\mathrm{SS}$ 농도로 하였고, $2.0 \mathrm{~mm}$ 이상 입경의 토 양시료는 제거하여 사용하였다.

토성이 같은 동일 토양시료를 이용하여 초 기 농도를 대략 $2,000 \mathrm{mg} / \mathrm{L}, 5,000 \mathrm{mg} / \mathrm{L}$, $20,000 \mathrm{mg} / \mathrm{L}$ 로 구분하여 농도별로 침강실험 을 하였다.

건조토양을 물과 함께 시험용기(칼럼)에 넣어 서 $1.6 \mathrm{~m}$ 가 되도록 하고, 충분히 섞은 후 와류 가 없어진 것을 확인한 뒤 측정을 시작하였다.

시료를 시험개시 후 미리 정한 시간 간격으 로 시료를 채취하여 부유물질량 $(\mathrm{SS})$ 를 분석하 였으며, 시료채취는 수면아래 $50 \mathrm{~cm}$ 에서 채취 하였다.

시료채취 시간은 기본적으로 $0,5,10,30$, $60,120,240,480,1440,2880$ 분마다 SS를 측정하고 $\mathrm{SS}$ 가 $25 \mathrm{mg} / \mathrm{L}$ 이하로 되는 시점까지 또는 최장 2 일 동안 시험을 계속하였다. 


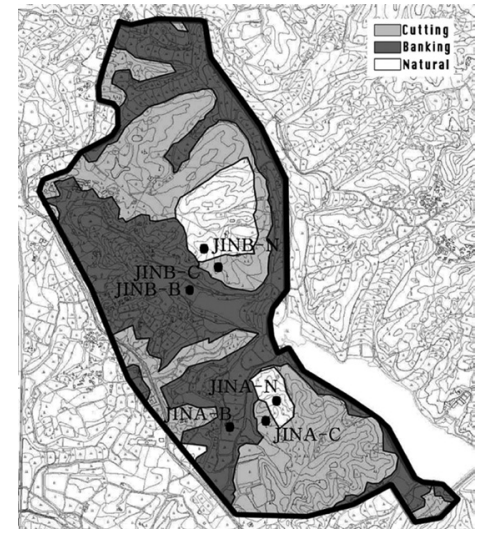

Jincheon Sinchuk

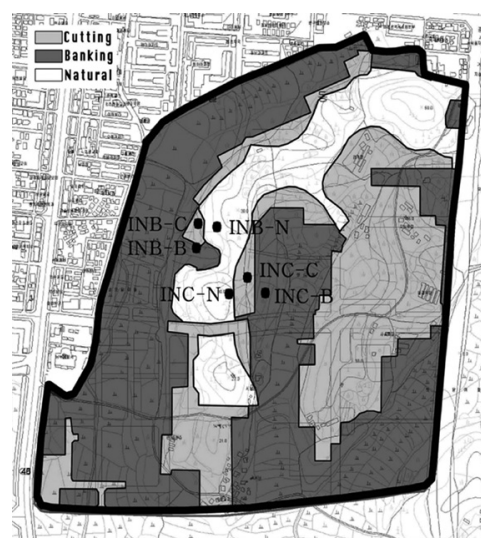

Incheon Guwall

Fig. 2.2. Sampling point.

\section{3 실험기구}

유실토양의 침강특성 실험시, 최대한 침사지 와 동일한 환경을 조성하기 위하여 column의 내경을 $190 \mathrm{~mm}$ 로, 칼럼의 수심은 $1.6 \mathrm{~m}$ 로 만 들어 실험을 실시하였다. 총 내부 시료량은 48 $\mathrm{L}$ 로 하였다.

시료의 채취는 수표면의 이물질의 영향을 배 제하고 웨어의 효과를 고려하여 수심 $50 \mathrm{~cm}$ 에 서 실시하였다.

\section{3. 결과 및 고찰}

\section{1 침사지 유입 토사 농도}

Park, Hee-Jun(2002)은 1997년부터 2002 년 시기의 단지개발사업 7건, 도로개발사업 8건 에 대해 유츌되는 부유토사(SS) 농도를 검토한
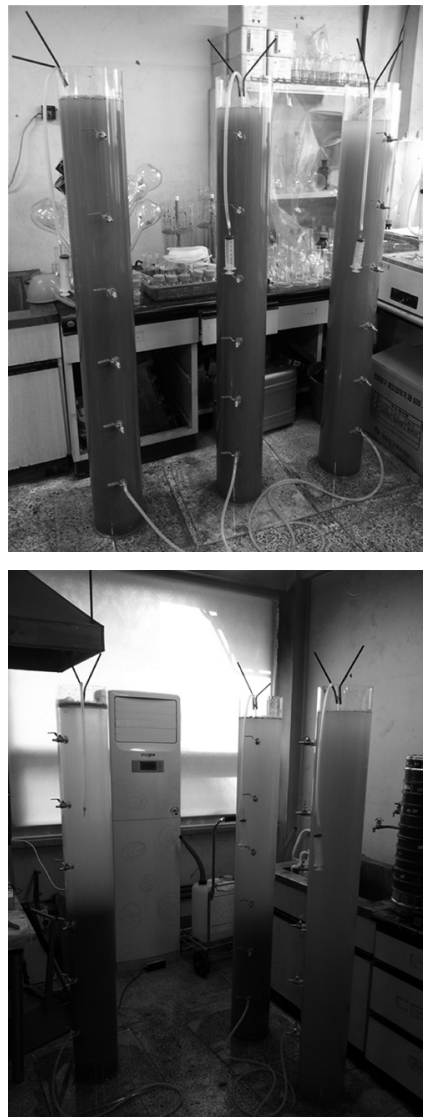

Fig. 2.3. Sedimentation test.

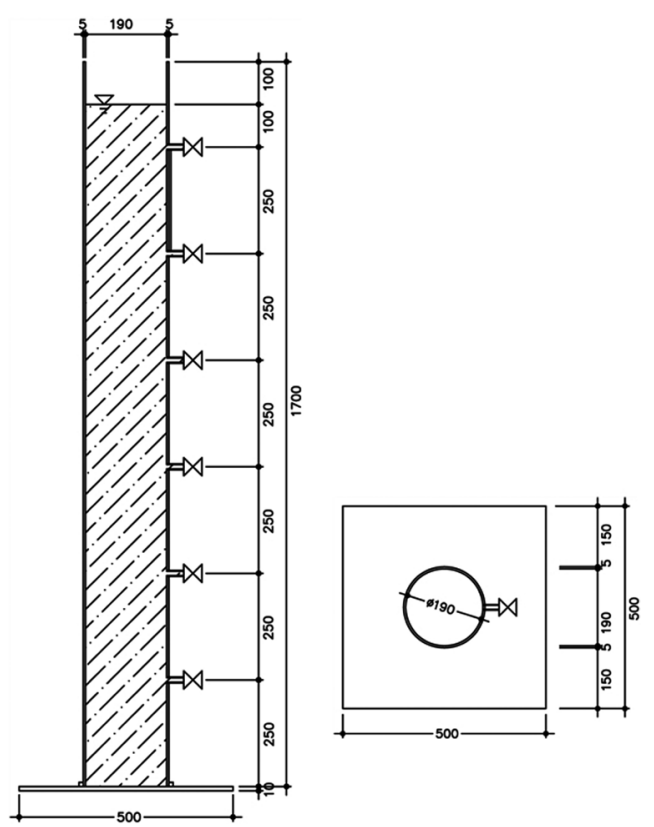

Fig. 2.4. Column of sedimentation test on top soil lost by a flood. 
결과 대부분 일본 정강현의“토지이용에 관한 지 도요강”에서 제시한 나대지의 토사유출 발생 원 단위인 $200 \sim 400$ ton $/ \mathrm{ha} / \mathrm{yr}$ 를 적용하고 있 으며, 유출되는 부유토사(SS)의 범위는 최소 82 $\mathrm{mg} / \mathrm{L}$, 최대 $1,589 \mathrm{mg} / \mathrm{L}$ 라고 제시하였다.

이는 일본 토질공학회의 “화학의 기초와 응용” 에서 제시한 택지 조성 공사시 유실토양 농도인 $200 \sim 2,000 \mathrm{mg} / \mathrm{L}$ 과 비슷한 경향을 나타낸다.

그러나 박선환(2008)은 농경지를 지나는 강 우초기 우수의 SS 농도가 3,400 14,450 mg/ L에 달한다고 제시하였으며, Huh, Tae-Jung (2011)은 건설현장에서 운영되고 있는 침사지의 유입수의 SS농도가 $790 \sim 7,570 \mathrm{mg} / \mathrm{L}$ (평균 $3,830 \mathrm{mg} / \mathrm{L}$ )에 달하는 것으로 제시하였다.

또한 Kim, Hyun-Young(2010)은 대전당진 고속도로 공사시 절성토 후 발생하는 우수유입수 의 $\mathrm{SS}$ 농도는 $1,165 \sim 3,900 \mathrm{mg} / \mathrm{L}$ 이라고 제시 한 반면 박희준(2002)은 경의선 공사중 토사유출 $\mathrm{SS}$ 농도가 $1,100 \sim 11,400 \mathrm{mg} / \mathrm{L}$ 라고 하였다.

실제 교란된 토지에서 유출되는 강우유출수 의 $\mathrm{SS}$ 농도는 토사유출 원단위법에 의한 농도보 다 높게 발생되고 있으며, 토사유출 원단위법에 의한 예측농도가 낮게 추정된 원인은 연간 강우 량 중 강수가 집중되는 시기에 토사유출도 집중 적으로 발생되게 되는데 이 현상을 반영하지 않 고 공사기간 중 일정비율로 유출되는 것으로 추 정한데서 발생되는 오류이며, 이 오류로 인하여 맑은 날도 토사의 유출이 있는 것으로 적용하게 된 데 그 원인이 있다.

본 연구지역에서 사후환경영향 조사시에 각 우수구역에 설치되어 있는 침사지의 유입농도를 조사하였다.

진천신척지역에서 2011년부터 2013년까지 침사지의 $\mathrm{SS}$ 농도를 조사한 결과 $\mathrm{A}$ 우수구역에 서 유입된 지표수의 SS는 $2.4 \sim 370 \mathrm{mg} / \mathrm{L}$, $\mathrm{B}$ 우수구역에서 유입된 지표수의 $\mathrm{SS}$ 는 4.0 $1,050 \mathrm{mg} / \mathrm{L}, \mathrm{C}$ 우수구역에서 유입된 지표수의 $\mathrm{SS}$ 는 $1.2 \sim 1,284 \mathrm{mg} / \mathrm{L}$ 로 조사되었다(Chung Buk development corporation, 2014).
이는 지표수의 SS는 강우와 토성과 밀접한 관 련이 있으며, 토양의 특성과 함께 공사공정에 따 라 토양의 교란정도가 다르므로 측정된 SS 농도 가 달라진 것으로 보인다.

또한 사후환경영향조사는 많은 경우 강우가 없는 시기에 지표수를 측정하여 강우 초기 유 입농도에 대한 결과를 알 수가 없었다. 그러나 2012년 7월과 8월에 다른 시기에 비해 높은 지 표수 $\mathrm{SS}$ 를 보인 것은 지표의 교란이 크게 일어 나는 공사공정이 이루어졌기 때문인 것으로 해 석된다(Fig 3.1).

인천구월지역에서 2012년부터 2013년까지 침사지의 $\mathrm{SS}$ 농도를 조사한 결과 $\mathrm{A}$ 우수구역에 서 유입된 지표수의 SS는 $17.0 \sim 136.0 \mathrm{mg} / \mathrm{L}$, $\mathrm{B}$ 우수구역에서 유입된 지표수의 $\mathrm{SS}$ 는 14.2 $98.0 \mathrm{mg} / \mathrm{L}$ 로 조사되었다(Incheon development \& tourism corporation, 2014).

대부분 강우가 없는 시기에 지표수를 측정하 여 지표수의 유입농도를 대표할 수 없는 것으로 조사되었으며, 토성과 공종에 따라 측정된 농도 가 달라지는 것을 알 수 있다.

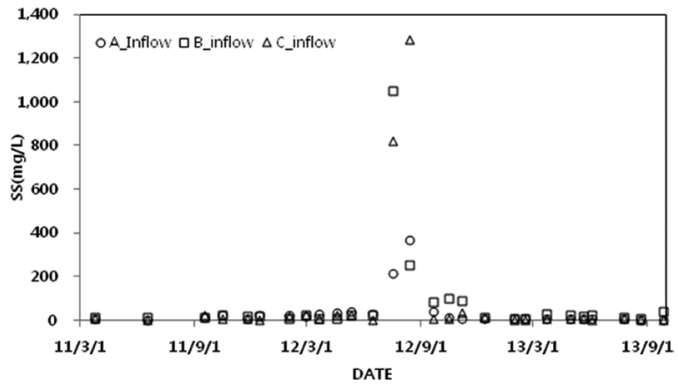

Fig. 3.1. Concentration of settling pond inflow at JincheonSinchuk.

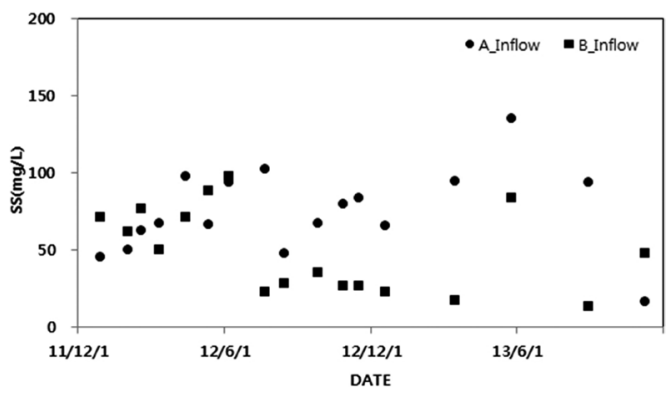

Fig. 3.2. Concentration of settling pond inflow at IncheonGuwall. 
따라서 침사지의 $\mathrm{SS}$ 농도는 강우와 토성, 공 사공정에 의한 토양교란정도와 밀접한 관계가 있어 공사시에 다양한 토사 농도에 발생시키고 있으며, 이러한 농도변화에 대해 적정한 침사지 를 계획하기 위해서는 토양의 침강특성을 미리 조사할 필요가 있다.

\section{2 유실토양 입경분포}

진천신척지역과 인천구월지역의 토양시료의 입경분포를 조사한 결과 $0.5 \mathrm{~mm}$ 이하의 입경에 서 인천구월지역의 토양시료가 차지하는 비율이 높게 조사되었다. 특히 $0.025 \mathrm{~mm}$ 이하 입경의 토양이 차지하는 비율에서 진천신척지역 토양은 $38.5 \%$, 인천구월지역 토양은 $45.6 \%$ 로서 인천 구월지역의 토양이 진천신척지역에 비해 입경이 작은 입자가 차지하는 비율이 높은 것으로 조사 되었다(Fig 3.3).

\section{3 유실토양 농도별 침강특성}

본 연구에서는 유실토양 방지를 위한 침사지 계획 시 동일지역에서 발생한 다양한 농도의 침 사지 유입수가 침강에 미치는 영향을 조사하기 위해서 실제 침사지와 유사한 침강실험을 실시 하였다.

연구 대상지역인 진천신척지역은 초기에는 상 징수의 농도 차이가 매우 컸으나 1 시간 이후에 는 $78 \sim 210 \mathrm{mg} / \mathrm{L}$ 로 상징수의 농도차이가 급 격히 감소하였으며 2 시간 이후에는 대부분 상징 수 $\mathrm{SS}$ 가 $50 \mathrm{mg} / \mathrm{L}$ 이하로 조사되었다(Fig 3.4).

인천구월지역도 초기의 상징수 $\mathrm{SS}$ 농도에 관 계없이 1시간 이후에는 $345 \sim 480 \mathrm{mg} / \mathrm{L}$ 로 상징수의 농도차이가 급격히 감소하였으며 이후 동일한 경향으로 간소하다가 8시간 이후에는 대 부분 상징수 $\mathrm{SS}$ 가 $100 \mathrm{mg} / \mathrm{L}$ 이하로 조사되었다

(Fig 3.5).

토양의 농도별 침강특성을 분석한 결과 농도 가 달라도 토양의 특성이 동일한 경우 그 침강 특성은 유사하였다. 초기의 상징수 농도가 달라
도 일정시간 $(1 \mathrm{hr})$ 이후의 상징수의 SS농도는 초 기농도에 관계없이 비슷한 경향을 보이고 있다.

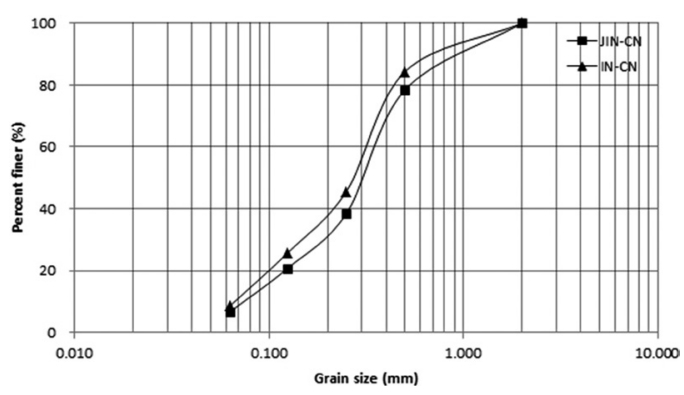

Fig. 3.3. Percent finer of soil sample.

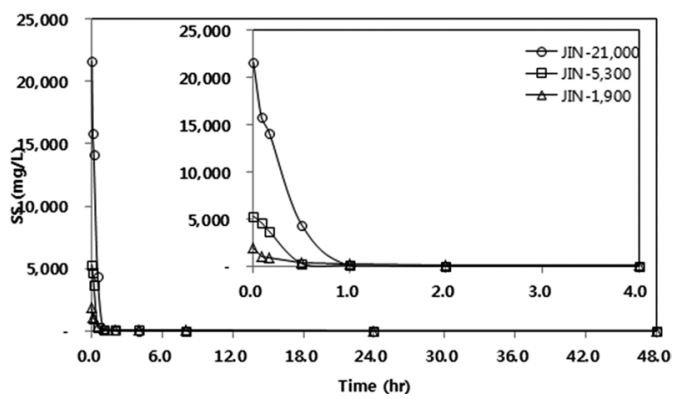

Fig. 3.4. Sedimentation characteristic of lost soil by soil concentration in JincheonSinchuk.

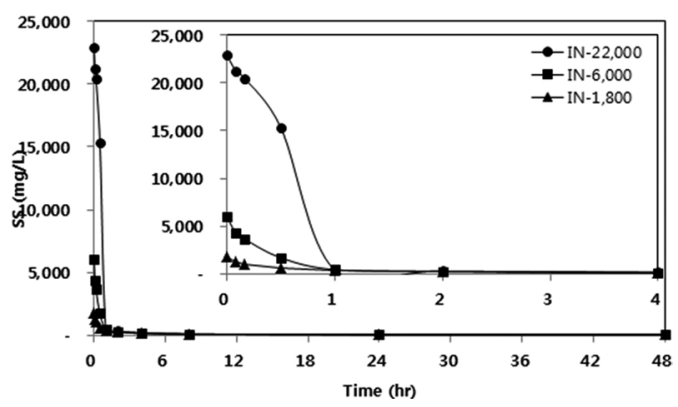

Fig. 3.5. Sedimentation characteristic of lost soil by soil concentration in IncheonGuwall.

\section{4 유실토양 지역별 침강특성}

입경의 분포가 다른 두 지역 토양시료의 침강 특성을 분석한 결과, 진천신척지역은 초기 농도 에 관계없이 1 시간 침강 후에 상징수 $\mathrm{SS}$ 농도는 $77.5 \sim 210 \mathrm{mg} / \mathrm{L}$ 로 그 차이가 줄었으며 2시간 후에 상징수는 $32.5 \sim 92.5 \mathrm{mg} / \mathrm{L}$ 로 조사 되었 
다. 4시간 이후에는 상징수의 대부분이 $50 \mathrm{mg} /$ $\mathrm{L}$ 이하로 조사되었다.

진천신척지역에 비해 미세입경의 비율이 높은 인천구월지역은 초기 농도에 관계없이 1 시간 침 강 후에 상징수 SS농도는 $345 \sim 480 \mathrm{mg} / \mathrm{L}$ 로 그 차이가 줄었으며 4시간 후에 상징수는 143.3 $\sim 200 \mathrm{mg} / \mathrm{L}$ 로 조사 되었다.

Fig. 3.7에 의하면 토양의 침강실험을 장기간 실시한 결과 진천신척지역은 4시간 이후에 상징 수는 $50 \mathrm{mg} / \mathrm{L}$ 이하로 되었으나 인천구월 지역 은 24 시간 이후에 상징수가 $50 \mathrm{mg} / \mathrm{L}$ 이하로 조 사되었다.

진천신척지역과 인천구월지역의 토양 침강특 성을 분석한 결과, 토성이 다른 토양의 경우 침 강경향은 비슷하나 침강속도 및 상징수 농도는 차이를 보였다.

유출수 $\mathrm{SS}$ 농도 $50 \mathrm{mg} / \mathrm{L}$ 를 위한 침사지를 계 획시 진천신척 지역은 약 4 시간의 체류시간이 필요하나 인천구월지역은 24 시간이 필요하다. 그러나 인천구월지역의 경우 침사지만으로 토사 유출을 억제하는 것은 비경제적이므로 일정시간 저류 후 유출수 농도를 제어할 수 있는 보조적 인 후단시설을 계획하는 것이 타당하다고 판단 된다.

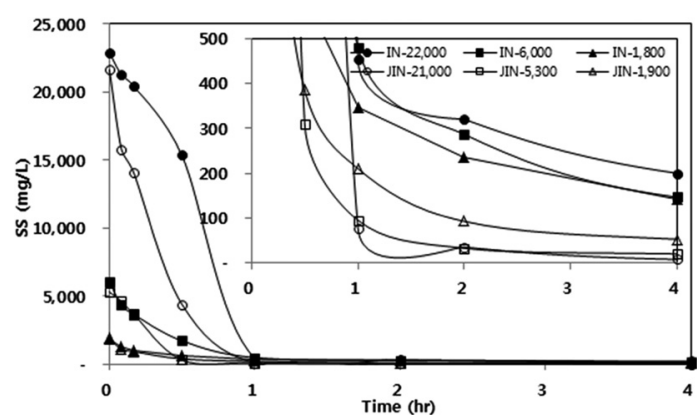

Fig. 3.6. Short term sedimentation characteristic of lost soil by area.

\section{4. 결 론}

1. 원단위법에 의한 방법에 의한 침사지 유입 수 토사농도는 SS $200 \sim 2,000 \mathrm{mg} / \mathrm{L}$ 이 나 실제 강우시 유입되는 토사의 농도는 각 지역과 공사공정에 따라 다양하여 원단위 법이 발생지역의 토성, 강우특성 및 공사공 정을 반영하지 못하고 있다.

2. 또한 공사시 실시한 사후환경영향조사 결 과 진천신척지역 침사지 유입수 $\mathrm{SS}$ 농도는 $1.2 \sim 1,284 \mathrm{mg} / \mathrm{L}$, 인천구월지역 14.2 $136 \mathrm{mg} / \mathrm{L}$ 로 강우시에 조사하지 않아 강 우시 침사지 유입농도 특성을 보여주지 못 하였다.

3. 초기 SS농도 대략 $2,000 \sim 20,000 \mathrm{mg} /$ $\mathrm{L}$ 범위에서 토양의 농도별 침강특성을 분 석한 결과, 초기농도는 달라도 시간의 경 과에 따라 농도 차이가 급격히 감소하였으 며, 동일토양의 경우 비슷한 침강특성을 보였다. 즉 초기농도에 관계없이 일정시간 침강후의 상징수의 $\mathrm{SS}$ 농도는 비슷한 경향 을 보였다.

4. 토양의 특성(입경분포)이 다른 경우 그 침 강속도 및 상징수 농도는 차이를 보였다. 진천신척지역은 4 시간 이후에 상징수 $\mathrm{SS}$ 농도는 $50 \mathrm{mg} / \mathrm{L}$ 이하로 되엇으나 인천구 월 지역은 24 시간 이후에 상징수 $\mathrm{SS}$ 농도 가 $50 \mathrm{mg} / \mathrm{L}$ 이하로 되었다.

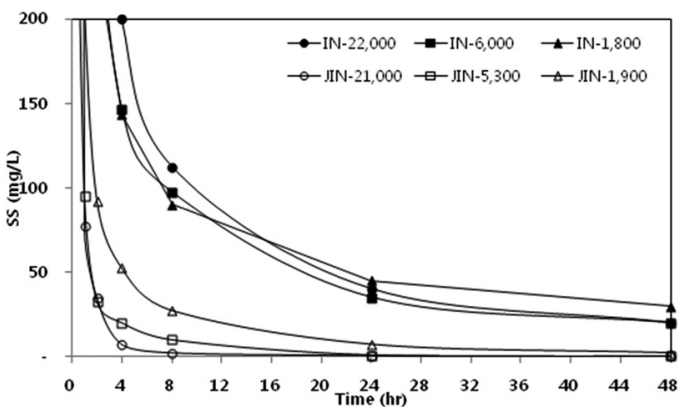

Fig. 3.7. Long term sedimentation characteristic of lost soil by area. 
5. 따라서 침사지 설계시 침사지 유입농도에 관계없이 토양침강실험에 의해 산출한 일 정 체류시간 이상으로 설계하고 추가적으 로 방류수 기준을 만족하기 위한 토사유출 저감시설을 후단에 계획하는 것이 토양유 실을 효과적으로 최소화할 수 있는 방안이 라고 판단된다.

\section{References}

Chung Buk development corporation (2014) Report of the environmental impact at Jincheon sinchuk industrial base during construction.

Huh, Tae-Jung (2011) A Study on Improvement of a Temporary Sedimen Basin Installation for Reducing Suspended Solid from a Construction Site, Seoul national university of science and technology, A master's thesis.

Incheon development \& tourism corporation (2014) Report of the environmental impact at Incheon guwall House business district during construction.

Kang, Chang-Hwan(2013) A study on the introduction of conservation of top soil into the environmental assessment system, Kwangwoon University, Department of Environmental Engineering, A thesis for a doctorate.

Kim, Hyun-Young (1987) Simulating daily inflow and release rates for irrigation reservoirs, Seoul national university, A thesis for a doctorate,

National disaster management institute (2008) Study on the sedimenr yield estimation due to land development( I ).

Park, Hee-Jun(2002) Relation analysis between soil grading and SS concentration of discharge water at bare area, Kwangwoon university, A master's thesis.

Park, Jong-Kwan(1993) Environmental Change of Suspended Sediment Discharge by Human Action, Journal of Environmental science international, 2(2), pp. 15-161.

Park, Sun-Hwan (2008) Impact of the geochemical characteristics and potential contaminants source of surrounding soil on contamination of a reservoir in an island (The case of a reservoir in Baengyeong island), Kwangwoon university, Department of environmental engineering, A thesis for a doctorate. 